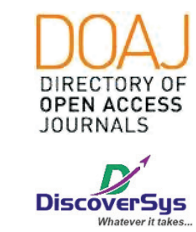

Published by DiscoverSys

\title{
Hubungan status kesehatan berdasarkan WOMAC dengan kualitas hidup berdasarkan WHOQOL-BREF pada pasien osteoartritis lutut di Rumah Sakit Sanglah tahun 2016-2017
}

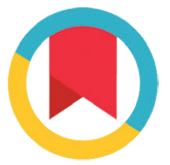

CrossMark

\author{
Ni Putu Ayu Pande Arista Dewi, ${ }^{1 *}$ Wayan Subawa, ${ }^{2}$ Agung Artha Wiguna ${ }^{3}$
}

\section{ABSTRACT}

Background: Osteoarthritis $(O A)$ is a chronic degenerative disease in joints. Limitations of body function experienced by patients with knee osteoarthritis is correlated with changes in quality of life. Quality of life is not only influenced by the physical condition of $0 \mathrm{~A}$ patients, but also influenced by mental and psychological. It is also important to be used for therapy in $\mathrm{AA}$ patients, not only in the clinical field, but mental and psychological fields of the patient should also be considered and become a benchmark in the success of a therapy.

Methods: This study was an analytic study with cross-sectional approach by finding correlation between independent variable (health status) with dependent variable (quality of life). The study sample was knee OA patients who had been diagnosed clinically and radiographically at Sanglah Hospital in 2016-2017. The research was conducted by visited subject's house and gave them two questionnaires.
Results: 38 respondents involved in this study, $26.3 \%$ were male and $73.7 \%$ were female. The results of this study show that: (1) There is a positive correlation $(r=0.345, p=0.034)$ between health status with quality of life, significantly, (2) while between each domain, there is significantly negative correlation $(r=-0.324, p=0.048)$ between health status and physical health domain at WHOQOL-BREF and a significantly positive correlation between health status and psychological $(r=0.328$, $p=0.044)$, social relationship $(r=0.325, p=0.047)$ environment domains $(r=0.530, p=0.001)$ at WHOQOL-BREF.

Conclusions: There is a significantly positive correlation between health status based on WOMAC score with quality of life based on WHOQOLBREF on knee OA patient at Sanglah Hospital in 2016-2017. The results of this study are expected to improve the quality of life can help knee $0 \mathrm{~A}$ patients therapy in order to achieve maximum therapeutic results.

Keywords: Health status, quality of life, WOMAC, WHOQOL-BREF

Cite This Article: Dewi, N.P.A.P.A., Subawa, W., Wiguna, A.A. 2018. Hubungan status kesehatan berdasarkan WOMAC dengan kualitas hidup berdasarkan WHOQOL-BREF pada pasien osteoartritis lutut di Rumah Sakit Sanglah tahun 2016-2017. Intisari Sains Medis 9(1): 71-75. D0I: 10.1556/ism.v9i1.164

ABSTRAK

Latar Belakang: Osteoartritis (OA) merupakan penyakit degeneratif pada persendian yang bersifat kronik. Keterbatasan fungsi yang dialami oleh penderita osteoartritis lutut berhubungan dengan adanya perubahan pada kualitas hidup. Kualitas hidup tidak hanya dipengaruhi oleh keadaan fisik dari penderita $O A$, namun juga dipengaruhi oleh mental dan psikis. Hal ini juga penting digunakan sebagai terapi secara menyeluruh bagi penderita $\mathrm{OA}$, tidak hanya dalam bidang klinis, akan tetapi bidang mental dan psikis penderita juga harus diperhatikan dan menjadi tolok ukur dalam keberhasilan suatu terapi

Metode: Penelitian ini merupakan penelitian analitik dengan pendekatan cross-sectional mencari hubungan antara variabel bebas (status kesehatan) dengan variabel tergantung (kualitas hidup). Sampel penelitian adalah pasien OA lutut yang telah terdiagnosis secara klinis dan radiografi di RSUP Sanglah pada tahun 2016-2017. Penelitian dilaksanakan dengan memberikan 2 kuesioner ke rumah masing-masing subjek.
Hasil: Dari 38 responden 26,3\% merupakan laki-laki dan 73,7\% merupakan perempuan. Hasil penelitian ini menunjukan bahwa: (1)Terdapat hubungan positif yang signifikan $(r=0,345, p=0,034)$ antara status kesehatan dengan kualitas hidup, (2) perbedaan hubungan rerata diantara masing-masing domain, dimana terdapat hubungan negatif yang signifikan $(r=-0,324$, $p=0,048$ ) antara status kesehatan dengan domain kesehatan fisik pada WHOQOL-BREF dan hubungan yang positif signifikan antara status kesehatan dengan domain psikologis $(r=0,328, p=0,044)$, hubungan sosial $(r=0,325, p=0,047)$ lingkungan $(r=0,530, p=0,001)$ pada WHOQOL-BREF.

Simpulan: Terdapat hubungan yang positif signifikan antara status kesehatan berdasarkan rerata skor WOMAC dengan kualitas hidup berdasarkan WHOQOL-BREF pada pasien OA lutut di RS Sanglah tahun 2016-2017. Hasil penelitian ini diharapkan dengan meningkatkan kualitas hidup dapat membantu terapi pasien $\mathrm{OA}$ lutut agar tercapai hasil terapi yang maksimal.
Program Studi Pendidikan Dokte, Fakultas Kedokteran Universitas Udayana

aristapande@yahoo.com
Received: 2018-01-31 Accepted: 2018-02-21 Published: 2018-02-25
Kata kunci: Status kesehatan, kualitas hidup, WOMAC, WHOQOL-BREF

Cite Pasal Ini: Dewi, N.P.A.P.A., Subawa, W., Wiguna, A.A. 2018. Hubungan status kesehatan berdasarkan WOMAC dengan kualitas hidup berdasarkan WHOQOL-BREF pada pasien osteoartritis lutut di Rumah Sakit Sanglah tahun 2016-2017. Intisari Sains Medis 9(1): 71-75. D0I: 10.1556/ism.v9i1.164 


\section{PENDAHULUAN}

Diantara penyakit rematik kronik OA memiliki angka prevalensi yang tertinggi ${ }^{1}$ dan salah satu penyebab kesakitan dan disabilitas bagi penderitanya. ${ }^{2}$ Pada umumnya OA banyak terjadi pada lansia (lanjut usia) akan tetapi tidak menutup kemungkinan juga terjadi pada kalangan muda yang disebabkan oleh aktivitas yang menimbulkan stress dan trauma pada persendian. Di Amerika OA menyerang $13,9 \%$ orang dewasa yang berumur $\geq 25$ tahun dan $33,6 \%$ berumur $\geq 65$ tahun. $^{3}$ Di Indonesia, prevalensi osteoartritis mencapai 5\% pada usia $<40$ tahun, 30\% pada usia 40-60 tahun, dan $65 \%$ pada usia $>61$ tahun. Berdasarkan diagnosis tenaga kesehatan NTT (Nusa Tenggara Timur) memiliki angka tertinggi sebanyak 33,1\%, jawa Barat 32,1\%, Bali 30\%, dan Jakarta 21,8\%. ${ }^{4}$

Berdasarkan data NHANES III, diantara penderita OA sekitar $80 \%$ penderita mengalami keterbatasan dalam pergerakan dan $25 \%$ mengalami keterbatasan dalam menjalani aktivitas sehari-hari. ${ }^{5}$ Keterbatasan fungsi yang dialami oleh penderita osteoartritis khususnya bagian lutut berhubungan dengan adanya perubahan pada kualitas hidup ${ }^{6}$ dan penelitian lainnya menyatakan perubahan pada kualitas hidup pada penderita osteoartritis merupakan salah satu konsekuensi langsung dari keterbatasan ruang gerak, nyeri, ketidakseimbangan otot, dan keterbatasan pada fungsi fisik. ${ }^{7}$

WHO mendefinisikan kualitas hidup sebagai persepsi individual mengenai posisi mereka dalam kehidupan dalam konteks nilai dan berhubungan dengan tujuan dan harapan. Faktor yang mempengaruhi kualitas hidup merupakan konsep yang luas dan mempengaruhi kehidupan yang lebih kompleks seperti kesehatan fisik, psikis, keyakinan, dan hubungan dengan lingkungan. ${ }^{8}$ Sehat tidak hanya dilihat dari ketidakhadiran suatu penyakit, namun juga dalam sehat fisik, mental dan psikis. ${ }^{9}$ Kualitas hidup tidak hanya dipengaruhi oleh keadaan fisik dari penderita OA, namun juga dipengaruhi oleh mental dan psikis. Hal ini juga penting digunakan sebagai terapi secara menyeluruh bagi penderita OA, tidak hanya dalam bidang klinis saja, akan tetapi bidang mental dan psikis penderita juga harus diperhatikan dan menjadi tolok ukur dalam keberhasilan suatu terapi. ${ }^{10}$ Salah satu penelitian mengenai hubungan kualitas hidup dengan $\mathrm{OA}$ lutut menyimpulkan bahwa terdapat hubungan antara kualitas hidup dengan status kesehatan, namun tidak semua penderita OA yang memiliki status kesehatan buruk ditemukan memiliki kualitas hidup yang buruk pula. ${ }^{6}$ Pengaruh penurunan kualitas hidup yang diakibatkan oleh OA berbeda dari setiap individu dengan individu lainnya dan tidak berbanding lurus dengan tingkat keparahan dan abnormalitas yang ditimbulkan akibat OA. ${ }^{11}$ Data seperti ini belum ada di Indonesia, khususnya di Bali.

Oleh karena itu, peneliti ingin melakukan penelitian mengenai hubungan antara status kesehatan dengan tingkat kualitas hidup pada pasien OA lutut di RS Sanglah pada tahun 2016 sampai dengan 2017 melihat pentingnya mengetahui keadaan pasien $\mathrm{OA}$ lutut tidak hanya dari keadaan klinis saja namun juga dari keadaan mental dan psikis. Status kesehatan dinilai menggunakan kuesioner WOMAC (Western Ontario and McMaster Universities Osteoartritis Index) yang menilai tingkat nyeri, kekakuan, dan fungsi fisik pada penderita OA lutut dan Kualitas hidup pada penderita OA bisa dengan menggunakan kuesioner WHOQOL-BREF.

\section{METODE}

Rancangan penelitian ini merupakan penelitian analitik dengan desain cross-sectional. Penelitian ini dilakukan di Poli Penyakit Dalam, Poli Ortopedi dan Rheumatologi RS Sanglah, dan rumah masing-masing pasien OA dari bulan Februari 2017 sampai Oktober 2017.

Populasi dalam penelitian ini adalah pasien OA lutut yang telah terdiagnosis secara klinis dan radiografi di RS Sanglah pada tahun 2016-2017. Sebanyak minimal 28 responden dipilih menggunakan teknik konsekutif sampling, yaitu semua pasien OA lutut yang sudah terdiagnosis secara klinis dan radiografi yang datang ke RS sanglah pada tahun 2016-2017 dan sudah memenuhi kriteria inklusi dan ekslusi akan digunakan sebagai responden dalam penelitian. Kriteria inklusi pada penelitian ini adalah responden dengan diagnosis $\mathrm{OA}$ lutut usia 40-70 tahun dan bersedia diikutkan dalam penelitian dengan menandatan-gani informed consent. Sedangkan kriteria ekslusi yang digunakan adalah responden obesitas IMT $>24,9 \mathrm{~kg} / \mathrm{m}^{2}$, telah menjalani operasi lutut (artroplasti total), memiliki riwayat penyakit penyerta, tidak mampu berjalan dan menggunakan alat bantu untuk berjalan.

Pemilihan responden penelitian dimulai dari mengambil data pasien di Poli Ortopedi dan Rheumatologi, dan Poli Penyakit Dalam, pasien yang memenuhi kriteria inklusi dan ekslusi selanjutnya akan dihubungi dan meminta persetujuan untuk diberikan kuesioner, jika bersedia, responden dikunjungi dan diminta menandatangani informed consent. Pasien diberikan dua kuesioner, yaitu kuesioner WHOQOL-BREF untuk menilai kualitas hidup dan kuesioner WOMAC untuk menilai status kesehatan. Kuesioner WHOQOLBREF terdiri dari 26 pertanyaan yang terbagi menjadi 4 domain, yaitu kesehatan fisik, psikologis, hubungan sosial, dan lingkungan. Masing-masing 
pertanyaan akan mendapatkan nilai $1-5$, dimana nilai 1 berarti sangat buruk dan 5 sangat baik selanjutnya akan dikategorikan, dimana $0-20=$ Kualitas hidup sangat buruk, 21-40= Kualitas hidup buruk, 41-60 $=$ Kualitas hidup sedang, $61-80=$ Kualitas hidup baik, $81-100=$ Kaulitas Hidup sangat baik. WOMAC memuat skala yang terdiri dari 3 subskala, yaitu nyeri (5 pertanyaan), kekakuan (2 pertanyaan), dan fungsi fisik (17 pertanyaan) selanjutnya nilai masing-masing pertanyaan dalam kuesioner WOMAC akan dirata-ratakan. Data yang telah dikategorikan kemudian dimasukkan ke dalam software input dan pengolahan data untuk kemudian dianalisis pada penelitian ini juga dibantu dengan menggunakan software excel dalam memasukan dan mengolah data. Kemudian data dianalisis menggunakan IBM SPSS 24 dan dilakukan analisis bivariate dengan menggunakan analisis korelasi pearson dan spearman untuk mencari hubungan rerata skor WOMAC dengan rerata skor WHOQOL-BREF.

\section{HASIL}

Sebanyak 38 data responden dianalisis dalam penelitian ini. Responden 26,3\% merupakan lakilaki dan $73,7 \%$ merupakan permpuan dan rerata umur seluruh subjek penelitian 63,32 \pm 8,00 tahun. Sebagian besar responden dengan tingkat pendidikan SMA (39,5\%) dan pendidikan tertinggi

Tabel 1 Klasifikasi skor WHOQOL-BREF

\begin{tabular}{lcc}
\hline & \multicolumn{2}{c}{ WHOQOL-BREF } \\
\cline { 2 - 3 } & \multicolumn{1}{c}{$\mathbf{r}$} & $\mathbf{p}$ \\
\hline WOMAC & 0,345 & $0,034^{*}$ \\
\hline Keterangan: ${ }^{*}$ Analisis data bernilai signifikan dengan tingkat kemaknaan $\mathrm{p}<0,05$ \\
Tabel 2 & Hubungan rerata skor WOMAC dengan rerata skor \\
& WHOQOL-BREF & \\
\hline Klasifikasi WHOQOL-BREF & $\mathbf{n}(\%)$ \\
\hline Sangat Buruk & $0(0)$ \\
Buruk & $1(2,6)$ \\
Sedang & $12(31,5)$ \\
Baik & $22(57,8)$ \\
Sangat Baik & $3(7,8)$ \\
\hline
\end{tabular}

adalah S1 (30.2\%) dan 2.3\% responden tidak sekolah. Sebagian besar (30.2\%) responden merupakan pensiunan. Diagnosis responden pada penelitian adalah OA Genu Bilateral, OA Genu Dekstra, dan OA Genu Sinistra sebanyak 46,5\%, 30,2\%, dan $11,6 \%$ secara berturut-turut. Rerata Indeks Masa Tubuh responden adalah $22,45 \pm 1,59 \mathrm{~kg} / \mathrm{m}^{2}$ dengan tinggi $162,08 \pm 5,40 \mathrm{~cm}$ dan berat badan $58,98 \pm 4,99$ $\mathrm{kg}$. Rerata score WOMAC adalah $0,47 \pm 0,97$. Rerata score WHOQOL-BREF adalah 64,18 $\pm 11,69$ dengan rerata domain kesehatan fisik 37,58 $\pm 8,71$; psikologis $75,00 \pm 14,15$; hubungan sosial $78,10 \pm 20,14$; lingkungan $66,24 \pm 18,60$.

Berdasarkan hasil penelitian klasifikasi kualitas hidup berdasarkan WHOQOL-BREF terdapat pada Tabel 1 yaitu, 2,6\% responden memiliki kualitas hidup buruk, 31,5\% memiliki kualitas hidup sedang, 57,8\% baik dan sangat baik sebanyak 7,8\%. Pada penelitian ini tidak didapatkan kualitas hidup sangat buruk (Tabel 1).

Pada penelitian ini didapatkan hubungan positif yang signifikan $(r=0,345, p=0,034)$ antara status kesehatan pada rerata skor WOMAC dengan kualitas hidup berdasarkan rerata skor WHOQOLBREF (Tabel 2).

Namun, terdapat perbedaan hubungan rerata diantara masing-masing domain. Pada penelitian ini didapatkan hubungan antara rerata skor WOMAC dengan domain kesehatan fisik pada WHOQOL-BREF berhubungan negatif yang signifikan $(r=-0,324, p=0,048)$. Didapatkan hubungan yang positif antara rerata skor WOMAC dengan domain psikologis $(r=0,328, p=0,044)$, hubungan sosial $(r=0,325, p=0,047)$ lingkungan $(r=0,530, p=0,001)$ secara signifikan (Tabel 3$)$.

\section{DISKUSI}

\section{Hubungan Status Kesehatan Berdasarkan WOMAC dengan Kualitas Hidup Berdasarkan WHOQOL-BREF}

Secara umum tingkat kualitas hidup pasien OA pada penelitian ini dikategorikan baik berdasarkan klasifikasi WHO dan adanya hubungan positif antara status kesehatan (tingkat nyeri, kekakuan dan keterbatasan) dengan kualitas hidup. Hal ini berarti tingginya tingkat nyeri, kekakuan dan keterbatasan

Tabel 3 Hubungan antara rerata skor WOMAC dengan rerata skor pada domain WHOQOL-BREF

\begin{tabular}{|c|c|c|c|c|c|c|c|c|}
\hline & \multicolumn{8}{|c|}{ WHOQOL-BREF } \\
\hline & \multicolumn{2}{|c|}{ Kesehatan Fisik } & \multicolumn{2}{|c|}{ Psikologis } & \multicolumn{2}{|c|}{ Hubungan Sosial } & \multicolumn{2}{|c|}{ Lingkungan } \\
\hline & $\mathbf{r}$ & $\mathbf{p}$ & $\mathbf{r}$ & $\mathbf{p}$ & $\mathbf{r}$ & $\mathbf{p}$ & $\mathbf{r}$ & $\mathbf{p}$ \\
\hline WOMAC & $-0,324$ & $0,048^{*}$ & 0,328 & $0,044^{*}$ & 0,325 & $0,047^{\star}$ & 0,530 & $0,001^{* *}$ \\
\hline
\end{tabular}

Keterangan: ${ }^{*}$ Analisis data bernilai signifikan dengan tingkat kemaknaan $\mathrm{p}<0,05$

${ }^{* *}$ Analisis data bernilai signifikan dengan tingkat kemaknaan $\mathrm{p}<0,01$ 
dalam melakukan aktivitas sehari-hari berdasarkan rerata skor WOMAC berhubungan secara signifikan $(p=0,034)$ dengan semakin tingginya angka kualitas hidup berdasarkan WHOQOL-BREF. Penelitian, ini tidak sesuai dengan penelitian dari Ivan Luis Andrade Araujo, dkk yang menyatakan adanya hubungan antara keterbatasan fisik dalam menjalankan kehidupan sehari-hari dengan kualitas hidup yang rendah pada pasien OA menggunakan kuesioner SF-36. ${ }^{7}$ Terjadinya perbedaan hasil antara status kesehatan (tingkat nyeri, kekakuan, dan keterbatasan) dengan kualitas hidup pada pasien OA lutut pada penelitian oleh Ivan Luis Andrade Araujo, dkk dengan penelitian ini karena terdapat perbedaan kuesioner yang digunakan. SF-36 merupakan salah satu kuesioner untuk menentukan kualitas hidup pada pasien OA, namun pada penelitian Paula Costra Casto yang melibatkan 278 subjek menyatakan bahwa WHOQOL-BREF lebih relevan digunakan pada subjek yang berumur lebih tua karena berkaitan dengan proses penuaan tanpa membandingkam ketidakmampuan fisik (kecacatan) dibandingkan SF-36. ${ }^{12}$ Penelitian serupa di Taiwan oleh Huang IC, menyatakan WHOQOLBREF lebih global dibandingkan SF-36 yang hanya menekankan pada kesehatan saja. ${ }^{13}$ Oleh karena itu pada penelitian ini kualitas hidup dengan WHOQOL-BREF lebih bersifat global. Penilaian tingkat status kesehatan (keterbatasan dalam aktivitas) pada penelitian Ivan Luis Andrade Araujo, dkk menggunakan Barthel index sedangkan peneltian ini menggunakan WOMAC dimana WOMAC lebih spesifik untuk menilai status kesehatan pasien OA dibandingkan Barthel index dimana menilai status kesehatan pada neuromuskular dan menekankan pada rehabilitasi. Janice Chaim Alves, dkk juga menyatakan hubungan yang negatif antara WOMAC dengan kualitas hidup berdasarkan WHO-OLD yang berarti semakin tinggi tingkat nyeri, kekakuan, dan keterbatasan fisik maka kualitas hidup akan semakin rendah, namun pada penelitian ini tidak ditemukan signifikansi antara korelasi rerata WOMAC dan WHO-OLD, pada jurnal ini juga didapatkan domain intimasi secara signifikan $(p=0,028)$ berhubungan yang berarti adanya kualitas hidup yang baik pada pasien OA walaupun dalam keterbatasan fisik dan tingkat nyeri yang tinggi dan domain kesehatan fisik saja tidak mencerminkan kualitas hidup seseorang. ${ }^{6}$

Kualitas hidup bersifat multidimensional dipengaruhi oleh budaya setempat dan melibatkan kesehatan fisik, material, sosial, lingkungan dan kesehatan mental. Dalam menilai kualitas hidup tidak bisa dinilai dari segi kesehatan saja namun harus dilihat secara menyeluruh. ${ }^{7}$ Konsep dan pemahaman mengenai pengertian kualitas hidup pada masing-masing individu berbeda, tergantung lingkungan, budaya, dan tingkat pendidikan. Pada penelitian yang dilakukan pada 93 pasien OA di Brazil menyimpulkan adanya perbandingan yang kuat antara pendidikan yang rendah dengan persepsi mengenai kualitas hidup yang rendah. ${ }^{10}$ Pada penelitian tesebut rata-rata kualitas hidup rendah dengan tingkat pendidikan SD (rendah) sedangkan pada penelitian ini rerata responden berpendidikan sampai lulus SMA dimana sebagian besar responden pada penelitian ini memiliki persepsi kualitas hidup yang cukup tinggi karena tingkat pendidikan yang lebih tinggi.

\section{Hubungan antara Status Kesehatan Berdasarkan WOMAC dengan Domain Kualitas Hidup pada WHOQOL-BREF}

Dari beberapa pertanyaan dalam domain kesehatan fisik, 57,8\% responden mengatakan keterbatasan fisik secara berlebihan mencegah dalam aktivitas sehari, $44,7 \%$ responden mengungkapkan sangat sering membutuhkan terapi medis, 57,8\% responden mengatakan tingkat kepuasan yang buruk dalam kemampuan bekerja dan adanya hubungan yang negatif antara status kesehatan (tingkat nyeri, kekakuan dan keterbatasan) pada rerata skor WOMAC dengan domain kesehatan fisik pada WHOQOL-BREF dengan yang berarti semakin tinggi tingkat status kesehatan (nyeri kekakuan, dan keterbatasan) pada pasien OA maka semakin buruknya rerata kesehatan fisik pada domain WHOQOL-BREF. Hasil penelitian ini sesuai dengan hasil penelitian di Family Medicine Department, Nigeria yang dilakukan oleh A.M Ogubonde dkk dimana nyeri pada OA mempengaruhi kesehatan fisik dan aktivitas sehari-hari. Selain itu juga didapatkan kesehatan fisik yang lebih buruk pada pasien OA dibandingkan pasien yang tidak OA. ${ }^{14}$ Penelitian serupa dengan 73 subjek mengenai nyeri, keadaan fisik, dan tingkat kesehatan pada pasien OA lutut dengan menggunakan kuesioner WOMAC juga dilakukan oleh Huang $\mathrm{KH}$, dkk dengan hasil status kesehatan berhubungan kuat dengan tingkat nyeri dan keterbatasan fungsi fisik. ${ }^{15}$ Penelitian yang menghubungkan kualitas hidup dengan domain nyeri pada Visual Analog Scale (VAS) dan WOMAC yang dilakukan oleh Berat Meryem Alkan, dkk menyatakan hubungan yang signifikan $(p<0,005)$ antara domain kesehatan fisik pada kualitas hidup dengan domain nyeri pada WOMAC, Laquesne, dan VAS. ${ }^{16}$

Kuesioner WHOQOL-BREF yang digunakan pada penelitian ini menilai kualitas hidup secara global sehingga tidak hanya dari kesehatan fisik, tetapi juga harus diperhatikan dari sisi psikologis, hubungan sosial, dan lingkungan. Pada penelitian ini di dapatkan hubungan yang positif antara kualitas hidup pada domain psikologis, hubungan 
sosial, dan lingkungan berdasarkan kuesioner WHOQOL-BREF dengan tingkat nyeri, kekakuan dan keterbatasan pada kuesioner WOMAC, berarti dengan tingginya tingkatan nyeri, kekakuan dan keterbatasan maka masih memungkinkan untuk mendapatkan angka kualitas hidup yang tinggi. Subjek pada penelitian ini sebagian besar merupakan pasien pre-operasi TKR yang sebagian besar stadium IV dan $\mathrm{V}$ dan menderita rasa nyeri dan kekakuan yang berat, namun responden mengatakan dukungan keluarga, teman, dan lingkungan sosial mereka menjelaskan bahwa walaupun dalam keadaan yang nyeri mereka tetap puas dengan keadaan mereka termasuk penampilan sehingga angka kualitas hidup akan meningkat. Penelitian oleh O. Ethgen, dkk menyimpulkan bahwa dengan adanya dukungan sosial $(p<0,005)$ akan mempengaruhi fungsi fisik $(p<0,001)$, mental $(p<0,001)$, dan kondisi umum kesehatan $(p<0,001)$ sehingga dapat meningkatkan kualitas hidup pada pasien OA lutut $(p<0,001)$. Salah satu hasil penelitian menyatakan adanya hubungan positif signfikan $(\mathrm{p}<0,001)$ terhadap kepercayaan tehadap kemampuan diri sendiri untuk tetap bertahan walaupun dalam kondisi nyeri dengan seluruh domain kualitas hidup berdasarkan WHOQOL-BREF, oleh karena itu, dengan meningkatkan dukungan sosial, psikologis, dan lingkungan akan meningkatkan kualitas hidup dan kepercayaan terhadap kemampuan diri sendiri walaupun dalam keadaan nyeri. ${ }^{17}$

Memperbaiki kondisi kesehatan dan menghilangkan rasa nyeri pada pasien OA dengan tetap menggunakan obat-obatan medis seperti antinyeri dan operasi jika sudah stadium akhir, namun dengan dukungan sosial dan mental dari keluarga maupun lingkungan akan meningkatkan hasil terapi pasien OA lutut. ${ }^{18}$ Kualitas hidup akan mempengaruhi pilihan terapi dan prosedur terapi pada pasien OA lutut. Pengobatan dengan antinyeri, perbaikan fungsi, dan peningkatan kualitas hidup pada pasien OA lutut menjadi bagian dari evaluasi efisiensi dan hasil dari suatu pengobatan pada pasien OA. ${ }^{7}$

\section{KETERBATASAN}

Penelitian lebih lanjut dengan melibatkan responden lebih banyak dan metode penelitian dengan cara pengambilan data yang lebih baik, akurat, dan pendataan yang lebih baik dan lengkap mengenai identitas dan diagnosis pasien sehingga jumlah responden yang terlibat lebih banyak.

\section{SIMPULAN}

Berdasarkan hasil penelitian didapatkan hubungan yang positif secara signifikan antara status kesehatan (tingkat nyeri, kekakuan, dan keterbatasan fisik) berdasarkan rerata skor WOMAC dengan kualitas hidup berdasarkan WHOQOL-BREF pada pasien OA lutut di RS Sanglah tahun 2016-2017. Dimana meliputi domain psikologis, hubungan sosial, dan lingkungan, sedangkan hubungan negatif secara signifikan pada domain kesehatan fisik.

\section{DAFTAR PUSTAKA}

1. Michael JW, Schluter-Brust KU, Eysel P. The epidemiology, etiology, diagnosis, and treatment of osteoarthritis of the knee. Dtsch Arztebl Int [Internet]. 2010;107(9):152-62.

2. Litwic A. Europe PMC Funders Group Epidemiology and Burden of Osteoarthritis. 2013;44(0):185-99.

3. CDC. Comorbidities of Osteoarthritis [Internet]. 2015 [cited 2017 Jan 2]. Available from: https://www.cdc.gov/ arthritis/data_statistics/comorbidities.htm

4. Sonjaya MR. Karakterisik Pasien Osteoarthritis Lutut Primer di poliklinik Ortopedi Rumah Sakit Al-Islam Bandung Tahun 2014. 2014;1:506-12.

5. Neogi T, Zhang Y. Epidemiology of OA. Rheum Dis Clin North Am. 2013;39(1):1-19.

6. Alves JC, Bassitt DP. Quality of life and functional capacity of elderly women with knee osteoarthritis Qualidade de vida e capacidade funcional de idosas com osteoartrite de joelho. Einstein (São Paulo). 2013;11(55 11):209-15.

7. Luis I, Araujo A, Castro MC, Daltro C, Matos MA. Quality of Life and Functional Independence in Patients with Osteoarthritis of the Knee. Knee Surg Relat Res. 2016;28(3):219-24.

8. WHO. Development of the World Health Organization WHOQOL-BREF quality of life assessment. The WHOQOL Group. Psychol Med. 1998;28(3):551-8.

9. WHO. Health [Internet]. 2016 [cited 2016 Sep 15]. Available from: http://www.who.int/about/definition/fr/ print.html

10. Kawano MM. Assessment of Quality of Life in Patients with Knee Osteoarthritis. Scielo. 2015;23(6):307-10.

11. Chan KKW, Wu RWK. Symptoms , Signs and Quality of Life ( QoL ) in. Intech. 2011;1:450-71.

12. Castro PC, Oishi J. Convergent validity between SF-36 and WHOQOL-BREF in older adults Validade convergente entre o SF-36 e o WHOQOL-BREF em idosos. Rev Saude Publica. 2014;48(1):63-7.

13. Huang IC, Wu AW F. Do the SF-36 and WHOQOL-BREF measure the same constructs? Evidence from the Taiwan population. PubMed. 2012;1(15):15-24.

14. Ogunbode AM, Adebusoye LA, Olowookere OO, Alonge TO. Original Article Physical Functionality and Self-Rated Health Status of Adult Patients with Knee Osteoarthritis Presenting in a Primary Care Clinic. Ethiop J Heal Sci. 2014;24(4):319-28.

15. Huang, Kuang Hui. Hsieah RL. Pain, Physical Function, and Health in Patient with Knee Osteoarthritis. Rehabiloitation Nurs. 2015.

16. Alkan BM. Quality of life and self-reported disability in patients with knee osteoarthritis. Mod Rheumatol. 2014;24(1):166-71.

17. Korff V. Prediction of Quality of life by Self-Efficacy, Pain Intensity and Pain Duration in Patient with Pain Disorders ${ }^{\star}, .2013 ; 4(2): 117-24$.

18. Ethengen O. Social support and health-related quality of life in hip and knee osteoarthritis. Qual Life Res. $2014 ; 12: 321-30$

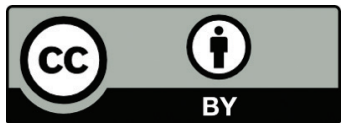

This work is licensed under a Creative Commons Attribution 